\title{
RAÍZES HISTÓRICAS DA DIFÍCIL EQUAÇÃO INSTITUCIONAL DA CIÊNCIA NO BRASIL
}

\author{
Ana Maria Alfonso-Goldfarb
}

Márcia H. M. Ferraz

\begin{abstract}
Resumo: Apresenta-se, neste artigo, o quadro histórico da institucionalização das ciências no Brasil, procurando identificar, em diferentes períodos, a articulação (ou falta de articulação) dos quatro componentes fundamentais para que ocorra a institucionalização de qualquer área do conhecimento, a saber: ensino, pesquisa, divulgação e aplicação do conhecimento.

Palavras-chave: ciência no Brasil; institucionalização da ciência; política científica.

Abstract: This article outlines the history of the institutionalization of the sciences in Brazil, highlighting, at different periods, the existence (or non-existence) of the four fundamental components necessary to institutionalize any area of knowledge: teaching, research, dissemination, and application of knowledge. Key words: science in Brazil; institutionalization of science; science policy.
\end{abstract}

A compreensão do modelo (ou da falta de modelo) para a institucionalização da ciência no Brasil passa, necessariamente, por uma análise histórica. Tradicionalmente, a imagem institucional da ciência brasileira foi alvo de comentários no exterior desde o século XIX. Em 1883, em artigo não assinado - mas, provavelmente, escrito pelo norte-americano Derby (1883:211) $-^{1}$ para a revista Science comenta-se que: "Os últimos dez ou quinze anos têm testemunhado um marcado despertar, no Brasil, para a importância da pesquisa científica e o início do que poderia muito bem ser designado como um novo movimento do qual, tanto quanto este autor saiba, nenhum registro foi, ainda, feito no exterior...".

Por um lado, o pano de fundo contra o qual se destacavam essas possíveis mudanças era constituído, segundo esse autor, por instituições frágeis e burocratizadas e uma pobre cultura bacharelesca, pois o governo, não tinha, "até recentemente, destinado uma bem direcionada e sustentável ajuda financeira a favor da investigação científica, ainda que tenha mantido, por muitos anos, com considerável despesa, departamentos científicos em todas as instituições superiores de ensino e em estabelecimentos como o observatório e o museu nacio- nais assim como organizando levantamentos e expedições de exploração" (Derby, 1883:212).

Por outro lado, o conhecimento científico das coisas brasileiras, quase sempre, foi de segunda mão, incompleto ou equivocado e sem nenhuma correção posterior, enquanto que as poucas contribuições nacionais eram isoladas e rudimentares devido à persistente falta de apoio oficial. Nas palavras de Derby (1883:212), "os próprios brasileiros, talvez em sua maior parte, desconhecem, o quanto é importante e promissora a atividade científica desenvolvida em seu meio por um pequeno grupo de empreendedores. Apesar de o Brasil [...] ter sido escolhido como o campo de pesquisa de um grande número de eminentes naturalistas estrangeiros, os brasileiros, à parte algumas poucas honoráveis exceções, se contentam em receber de segunda mão o conhecimento da história natural de seu próprio país e raramente se dedicaram, em seu próprio benefício, a suplementar e corrigir o trabalho dos naturalistas estrangeiros, muitos dos quais são, obviamente, incompletos e equivocados. Devido à organização inadequada ou apoio insuficiente, os resultados de todos esses esforços têm sido, entretanto, de pequeno valor". 
Derby, possível autor desse artigo, sabia muito bem do que estava falando, conhecedor que era da situação brasileira, pois havia fixado residência em nosso país em 1875, trabalhando, em diferentes grupos relacionados com a ciência (Leinz, 1954:251-2). Pois, efetivamente, cada uma das críticas feitas por ele tinha raízes no período colonial. Conforme é bem conhecido, a institucionalização da ciência depende, sobretudo, de quatro componentes, a saber: ensino, pesquisa, divulgação e aplicação do conhecimento. No entanto, contar a história desses componentes no período colonial é contar a história de sua negação.

O binômio estudar/ensinar foi, sem dúvida, um dos piores da época colonial. De fato, as atividades dos padres da Companhia de Jesus representavam, até 1759 - quando os inacianos foram expulsos de todo o reino Português -, a maior parcela do sistema educacional no Brasil. De toda forma, essas atividades restringiam-se, fosse a ensinar a ler e a contar nas escolas de primeiras letras, fosse, em seus colégios, à educação básica no que se denominava letras e artes - a ser completada em universidades européias - na formação de quadros para a Companhia. A ordem de expulsão dos jesuítas, com o conseqüente fechamento de seus colégios, trouxe, para a Colônia, o desmantelamento do sistema de ensino. Essa situação durou mais de uma década, até que fossem instituídas as aulas régias, que eram, na verdade, disciplinas isoladas ministradas por ex-alunos dos colégios jesuíticos. Todos os esforços dos padres da Companhia de Jesus para expandir suas atividades de ensino - em cursos do ensino superior, por exemplo - foram frustrados pelo governo português que tinha como forte propósito impedir o estabelecimento de instituições que pudessem rivalizar com as existentes na Metrópole.

Anteriormente, as insistentes solicitações dos jesuítas para equiparar seu Colégio da Bahia ao Colégio que mantinham em Évora, Portugal ou, ainda à Universidade de Coimbra, foram todas negadas (Alfonso-Goldfarb e Ferraz, 1988:344-5). Não era do interesse do governo que aqui se estabelecessem cursos de nível superior, não importava de quem partisse a solicitação. Nesse sentido, em 1768 o Conselho Ultramarino nega o pedido encaminhado pelos habitantes de Minas Gerais para criar, a suas expensas, um curso superior de medicina. A justificativa deixava claro que "um dos mais fortes vínculos que sustentava a dependência das colônias, era a necessidade de vir estudar a Portugal" (Cunha, 1993:72). De fato, apenas em 1808, com a transferência da sede do
Reino Português para sua colônia na América, foi autorizada a instalação dos primeiros cursos de ensino superior no Brasil. Assim, ainda durante a curta estada na Bahia - antes de se dirigir à cidade que deveria ser a sede da Coroa - D. João, o Príncipe Regente, atendeu aos apelos de José Correia Picanço, médico nascido no Brasil e nomeado cirurgião-mor do Reino, e fez promulgar uma carta régia que criava uma "Escola de Cirurgia no Hospital Real desta Cidade [da Bahia], para instrução dos que se destinam ao exercício desta arte". Já no Rio de Janeiro, cerca de um mês mais tarde, o Príncipe Regente assina uma outra carta régia com objetivos semelhantes: dotar a cidade de um curso para formar os profissionais - médicos e cirurgiões - exigidos pela nova situação, com o aumento repentino da população.

Importante observar, entretanto, que esses cursos de medicina não eram equivalentes ao que se desenrolava na Universidade de Coimbra; nos dois casos as cadeiras, ou seja, as disciplinas da carreira médica foram sendo instaladas paulatinamente. Faltavam professores capacitados para ensinar as diversas disciplinas e, por outro lado, os alunos que se destinavam a tais cursos tinham uma formação deficitária que impedia o pleno desenvolvimento dos estudos. Passadas várias décadas, o plano original das cadeiras de ensino não havia sido completado e os "médicos malformados" passavam a disputar com seus colegas egressos de escolas européias (Ferraz, 1997:191-200). Nas palavras do diretor do curso estabelecido no Rio de Janeiro, a falha estava em permitir ao aluno "começar estudos tão árduos ao sair da escola das primeiras letras, exigindo-se apenas algum conhecimento da língua francesa, sem arte de discorrer, sem hábito de estudar e compreender e sem preliminares que o habilite para estudar ciências que jogam com princípios de Física, Química e Filosofia Geral que, ademais, se acham escritos em línguas que ignoram" (Andrade, 1827).

Ao se lembrar das proibições até então em vigor para a instalação de qualquer curso que pudesse rivalizar com os da metrópole, não é de se estranhar nem a dificuldade para encontrar professores, nem a imperícia dos estudantes, não sendo possível exigir mais de suas parcas habilidades.

Deve-se ressaltar que, durante certo período, na Universidade de Coimbra de finais do século XVIII, os "brasileiros" formavam o maior contingente no Curso Filosófico no qual se realizavam os estudos das ciências naturais. Alguns deles, colocados a serviço do governo português para desenvolver atividades ligadas ao estudo e aprovei- 
tamento das produções naturais, haveriam de se destacar e tornaram-se conhecidos mesmo fora de Portugal. É o caso por exemplo, de José Bonifácio de Andrada e Silva - mais conhecido em nosso país como o Patriarca da Independência - que ocupou diversos cargos junto às instituições portuguesas de estudo, ensino e aplicação do conhecimento em ciência, como a Academia Real das Ciências de Lisboa, a Universidade de Coimbra e a Casa da Moeda de Lisboa. À sua terra natal, entretanto, só lhe é permitido voltar em 1819 e uma vez no Brasil, pouco se dedicou à ciência (Alfonso-Goldfarb e Ferraz, 1990:767; Ferraz, 1997:163-7).

Ao lado da medicina, a formação de oficiais e engenheiros que pudessem se dedicar "à defesa e segurança [dos] vastos domínios", era uma outra preocupação do governo que se instalava no Brasil. Pensando nisso, D. João faz promulgar em 1810 uma carta régia criando a Academia Real Militar, onde funcionaria: "um curso completo de ciências matemáticas, de ciências de observações, quais a química, física, mineralogia, metalurgia e história natural que compreenderá o reino vegetal e animal, $[\ldots]$ assim como de todas aquelas [ciências] que são aplicação das mesmas aos estudos militares e práticos que formam a ciência militar em todos os seus difíceis e interessantes ramos [tanto tática como fortificação e artilharia], de maneira que dos mesmos cursos de estudos se formem hábeis oficiais de artilharia, engenharia e ainda mesmo oficiais da classe de engenheiros geógrafos e topógrafos, que possam também ter o útil emprego de dirigir objetos administrativos de minas, de caminhos, portos, canais, pontes, fortes e calçadas" (Moacyr, 1936:46-7).

Essa carta régia dá detalhes sobre como deveria funcionar o curso em seus sete anos, do programa das diferentes cadeiras, dos autores e obras que deveriam ser seguidos, entre outras questões. Tem-se, mais uma vez, infelizmente, que mencionar os muitos problemas que acompanharam o estabelecimento dessa instituição: falta de um prédio com instalações adequadas e equipadas, dificuldade para contratar professores, quase total inexistência de livros. Por certo, até 1832: "Não se haviam posto em completa execução os estatutos e não tivera o devido desenvolvimento a teoria das construções, não se haviam verificado os exercícios práticos e nem se atendera a organização dos compêndios determinada na lei de criação do estabelecimento" (Azevedo, 1877:43-4).

Se pouco pode-se falar sobre investigação é porque nessas escolas, já no século XIX, existia uma visão ape- nas profissionalizante. Enquanto que as tentativas de formar academias ou outros centros voltados à discussão ou pesquisa - pautadas no modelo inglês ou francês - foram também frustradas durante o período colonial (AlfonsoGoldfarb e Ferraz, 1988:345).

Olhando para esse quadro anterior, relativo à investigação e ao ensino, é possível tocar em outro dos componentes apresentados anteriormente: a divulgação. Ou seja, um dos aspectos fundamentais para que o binômio ensino/investigação estenda-se e frutifique na sociedade. Entretanto, durante o período colonial, qualquer manifestação para instalar-se prelos no Brasil foi sistematicamente reprimida pelo governo português. Uma dessas tentativas tornou-se bem conhecida e merece ser comentada: tratase da iniciativa de Antônio Isidoro da Fonseca sufocada em 1747 tão logo sua notícia chegou a Lisboa. O tipógrafo havia trabalhado durante um período em Portugal imprimindo obras importantes, e foi considerado muito habilidoso. Não há um consenso sobre as razões pelas quais ele teria sido proibido de exercer suas atividades no Brasil - diz-se mesmo que ele teve problemas com a Inquisição por ter editado obras de Antônio José da Silva, conhecido como "O Judeu". Uma das razões, provavelmente a principal, é fornecida pelo próprio governo português, que considerava inconveniente a instalação de prelos no Brasil, já que toda publicação deveria ter a licença da Inquisição e do Conselho Ultramarino, sediados na Metrópole, devendo, assim, toda impressão ser feita em Portugal (Hallewell, 1985:13-20).

De qualquer modo, a ordem real que proibiu o trabalho do impressor no Rio de Janeiro dizia que: "não se imprimissem livros, obras ou papéis alguns avulsos, sem embargo de quaisquer licenças que tivessem dita impressão, sob pena de que, fazendo o contrário, seriam remetidos presos para o Reino para se lhes impor as penas em que tivessem incorrido, de conformidade com as leis e ordens a respeito" (Apud Sodré, 1977:20).

Como se verá, o que poderia ser lido na Colônia era bastante controlado pelo governo, não apenas proibindo os prelos e decidindo sobre o material a ser publicado, mas também mantendo mão férrea sobre o que entrava no país. Assim, o porto era uma barreira muito difícil de ser transposta: os navios eram inspecionados antes de atracar e quase todos os textos impressos eram jogados ao mar. A lista dos livros proibidos - de serem impressos, comercializados, lidos e guardados - em finais do século XVIII incluía obras de Locke, Rousseau, Voltaire, Bayle e Hobbes, entre muitos outros (Bastos, 1983:44; 59 e seg.). 
O parecer de um dos membros da Real Mesa Censória que em finais do século XVIII decidia sobre o que poderia ser publicado em Portugal diz, especialmente sobre o trabalho de Locke: "Já há muito tempo que eu tenho feito bastante reflexão sobre a Filosofia do Sr. João Locke no seu célebre Tratado do entendimento humano. [...] deixando ao filósofo inglês todo o seu merecimento que pertence às suas meditações filosóficas, pelo que respeita à Religião, sou em tudo do mesmo parecer [...] que não deve esta Mesa deixá-lo correr, porque é muito perigosa a sua doutrina, e não há para que Membro algum deste Tribunal se empenhe a fazer-lhe Apologias, e explicar em bom sentido as suas duríssimas expressões pois não há no Livro Canônico, nem Santo Padre da primitiva Igreja a quem se deva essa veneração. O sr. Locke no juízo de muitos Eruditos é notado favorecer o Materialismo, esse Monstro, que tanto ruína o século presente com ruína grande da Religião" (Bastos, 1959:88).

A Bíblia em português faz parte das diferentes listagens desde o século XVI e só passou a ser publicada em vernáculo em 1778 e apenas na Metrópole, continuando a ser proibida em nosso país (Hallewell, 1985:4).

Temia-se, por um lado, a difusão de idéias que pudessem levar à independência e, por outro, que se divulgassem as riquezas da colônia americana propiciando, assim, a cobiça entre estrangeiros e reinóis.

A obra de André João Antonil - codinome do jesuíta italiano João Antônio Andreoni vindo ao Brasil a convite do Padre Antônio Vieira -, Cultura e opulência do Brasil, publicada em 1711, foi recolhida e queimada. Certamente, o texto, por conter informações importantes sobre as riquezas do Brasil - como a produção do açúcar, o tabaco e o gado bovino, mas, sobretudo, as minas de ouro, incluindo a localização e a maneira de minerar o metal -, representava um perigo para o governo português. ${ }^{2}$

Da mesma forma, as memórias encomendadas pelo governo português aos naturalistas, sobretudo a partir do último quartel do século XVIII, deveriam permanecer secretas, depositadas em arquivos, fossem os da Academia das Ciências de Lisboa fossem os oficiais. Os relatos desses naturalistas tratavam, quase sempre, da descrição geográfica dos locais por onde passavam, dos plantios realizados pelos habitantes da terra e, ainda, de suas explorações extrativas, fossem minerais ou vegetais. Davam ênfase à possibilidade de utilização dos produtos nativos com destaque para o reconhecimento e análise de minerais e de metais. Não deixavam de descrever as plantas para uso medicinal, sem esquecer aque- las importantes para a tinturaria e a saboaria (Ferraz, 1997:169 e seg.).

O Brasil foi tema de grande massa de relatos, elaborados, muitas vezes, por "Brasileiros" empenhados em fazer o reconhecimento de sua terra, como são Alexandre Rodrigues Ferreira, João da Silva Feijó e José Vieira Couto. $\mathrm{Ou}$, ainda, Manuel Arruda da Câmara e José Mariano da Conceição Veloso. ${ }^{3}$

Tem-se, também, certo número de textos elaborados sobre o Brasil por estrangeiros nos primeiros séculos da colonização da América, como os de André Thevet e Jean de Léry no século XVI. Ou, ainda, os de Wilhelm Piso e George Marcgraff, estudiosos que estiveram, no século XVII, com Maurício de Nassau, no nordeste do país. ${ }^{4}$ Apenas a "abertura" dos portos, com a mudança da Corte Portuguesa para o Brasil em 1808, permitiu a entrada de estrangeiros que puderam percorrê-lo com certa liberdade. Ao elaborarem seus extensos relatos deram a conhecer ao mundo a terra brasilis. Escritos e publicados, entretanto, em suas línguas maternas, pouco foram lidos por portugueses e brasileiros até o início do século XX, quando muitos dos textos foram traduzidos à nossa língua (Alfonso-Goldfarb e Ferraz, 1988:347).

Ao se associar os diversos fatores - por um lado, uma política que procurava impedir a divulgação dos trabalhos em português e, por outro, a dificuldade em ler em língua estrangeira, sem contar o analfabetismo que até hoje condena uma boa parte da população (Alfonso-Goldfarb, Ferraz e Figueirôa, 1997) -, tem-se que o Brasil foi, durante longo período, muito mais conhecido por estrangeiros do que por brasileiros (Alfonso-Goldfarb e Ferraz, 1999), ainda que os trabalhos sobre o país contivessem muitos equívocos, como bem observa Derby, citado anteriormente.

Apenas em 1808 se instalam definitivamente os prelos no Brasil, enquanto algumas das regiões espanholas na América, como as que passariam a ser chamadas de México e Peru, já desde o século XVI puderam contar com a imprensa em seus territórios (Sodré, 1977:12). Por incrível que pareça, esse será um benefício trazido pela desgraça do reino português quando da invasão francesa. Nessa época, uma tipografia recém-adquirida na Inglaterra encontrava-se no cais de Lisboa e foi embarcada em um dos navios que deixavam Portugal fugindo das tropas de Napoleão. Instalada no Rio de Janeiro, foi posta a funcionar mediante decreto do Príncipe Regente que dizia: "Tendo-me constatado que os Prelos que se acham nesta Capital eram os destinados para a Secretaria dos Negócios 
Estrangeiros e da Guerra, e atendendo à necessidade que há de uma oficina de impressão nestes meus estados: Sou servido que a casa onde eles se estabeleceram sirva interinamente de Impressão Régia, onde se imprimam exclusivamente toda a Legislação, e papéis diplomáticos que emanarem de qualquer repartição do meu Real Serviço e se possam imprimir todas e quaesquer obras." (Correio Braziliense, 1808:517-8).

A instalação da Impressão Régia foi elogiada como um primeiro passo para a liberdade de imprensa, segundo o comentário de Hipólito José da Costa, editor do Correio Braziliense que reproduziu no número de novembro de 1808 o decreto já citado. Esse periódico, ainda que destinado ao Brasil era, entretanto, impresso em Londres para livrar-se da censura portuguesa. Não fosse assim, estaria sujeito às mesmas restrições que pesavam sobre a Gazeta do Rio de Janeiro, órgão oficial saído dos prelos da Impressão Régia de 1808 a 1822: apenas os avisos da Corte tinham livre curso; todo material político, jurídico e mesmo religioso era cuidadosamente examinado temendo-se, sobretudo, que as idéias de independência ganhassem corpo entre os habitantes do Brasil (Alfonso-Goldfarb e Ferraz, 1988:349).

De qualquer forma, a Impressão Régia foi fundamental nos primeiros anos de instalação dos cursos superiores no Brasil, pois deu ao público uma boa parte dos livros indicados para o ensino da medicina e da engenharia. São, principalmente, traduções do francês, encontrandose, também, textos escritos em português. Para dar alguns exemplos pode-se citar Legendre, Fourcroy, Haüy, Lacroix e Euler - entre os autores estrangeiros - ao lado de José Maria Bomtempo e Manuel Ferreira de Araújo Guimarães. ${ }^{5}$

$\mathrm{Na}$ verdade, embora não seja tão evidente como o binômio ensino/investigação, a divulgação do conhecimento por meio da imprensa também forma um binômio com a aplicação do conhecimento. Uma vez que será justamente pela divulgação das pesquisas e da ampliação do ensino que se torna possível desenvolver uma atividade produtiva própria a um país.

Pode-se ver essa questão no capítulo do que seria a aplicação do conhecimento sobre as plantas, cuja extração serviria para a produção de fármacos tão valorizados em toda a Europa. Voltando a um dos autores citados anteriormente, José Maria Bomtempo, nomeado professor de uma das cadeiras de medicina no Rio de Janeiro, que compôs para seus alunos os Compêndios de Matéria Médica. O autor, nesse texto, segue de perto as idéias de Darwin, que classificava as doenças em apenas quatro tipos, o que deveria facilitar a prescrição dos remédios. Bomtempo restringe ainda mais a lista dos materiais medicamentosos apresentada por E. Darwin e quanto aos vegetais de origem brasileira, cita apenas a copaíba (Ferraz, 2000:176-8).

Isso não seria por falta de informações pois, B.A. Gomes, médico que em finais do século XVIII havia viajado pelo Brasil durante dois anos, já fizera publicar, em Portugal, uma memória sobre as plantas autóctones (Gomes, 1812). Nesse trabalho Gomes critica os médicos que no Brasil insistiam em curar as enfermidades locais valendo-se da medicina européia. Seu estudo de quinze plantas brasileiras é, de fato, uma proposta para o desenvolvimento de uma matéria médica especialmente dedicada a nosso país. ${ }^{6}$ Bomtempo, cuja obra estende-se até os anos 30 do século XIX - influindo, assim, nos estudos médicos já no Brasil independente -, segue uma via completamente diferente daquela proposta por Gomes, nos estudos sobre a quina, por exemplo. Enquanto Gomes acreditava que as análises químicas desse vegetal poderiam ajudar na difusão de seu uso médico, Bomtempo criticava severamente o que considerava seu uso descontrolado no Brasil. Os naturalistas estrangeiros, entretanto, ao seguirem a via aberta pelos trabalhos de Gomes, e diferentemente de Bomtempo, consideram que a flora do Brasil, variada e cheia de novidades, não apenas apresentava os princípios ativos adequados para as enfermidades de nosso país, como também poderia contribuir para ampliar a matéria médica em geral (Gomes, 1812; Bomtempo, 1814; Alfonso-Goldfarb e Ferraz, 1999a:47-8).

Se, no caso das plantas havia, por parte dos portugueses, um descaso em conhecê-las e utilizá-las, os minerais representavam a mais alta cobiça e sua exploração exitosa era o mais desejado. O pior, talvez, dos problemas para a aplicação dos conhecimentos da terra brasilis à exploração mineral tenha sido o do minério de ferro. Por apresentar um alto teor metálico, o ferro transforma o que deveria ser uma bênção em um problema, pois as técnicas metalúrgicas então conhecidas levavam ao consumo de grande quantidade de carvão para um pequeno rendimento em metal. Era premente estabelecer procedimentos que, associando teoria e prática, levassem em conta as condições em nosso país. Dessas particularidades se apercebeu Couto, citado anteriormente, que fala, em memória escrita em 1799 do "estado atual e decadente da mineração no Brasil" devido, por um lado, à "ignorância dos mineiros, 
e o descuido de se instruir com tempo na sua profissão" e, por outro, à falta de máquinas próprias para o tipo de operação a ser realizada o que levava a um trabalho desgastante dos escravos e a uma pequena quantidade de metal. Havia, segundo o autor a "necessidade de uma Arte metalúrgica nacional", que seria "fundada em experiências feitas sobre as próprias minas e sobre os fundentes do país" (Couto, 1994:71; Alfonso-Goldfarb e Ferraz, 1990:87-8).

Essa voz, entretanto, exatamente como outras de súditos portugueses, permaneceu sem eco no governo. $\mathrm{O}$ método do cadinho - trazido por escravos africanos da costa oriental, onde o haviam aprendido em seu intercâmbio com o mundo árabe - continuou a ser utilizado em larga escala no Brasil, em uma época em que já se conheciam técnicas mais eficientes para o trabalho com o ferro. Há registro de abandono de uma forja italiana por falta de quem a tocasse quando o responsável a deixou; os escravos disponíveis não conheciam a técnica exigida e não havia ninguém que a pudesse ensinar-lhes (Baeta, 1973:137).

Quando, já no século XIX se introduzem os alto-fornos para a obtenção do ferro, os problemas subsistem, pois esses estavam projetados para as condições européias. Assim, vários anos foram necessários para conseguir algum produto na fábrica do Morro do Pilar em Minas Gerais, instalada com dinheiro da Coroa sob a direção de Manuel Ferreira da Câmara, que havia estudado mineração e metalurgia na Europa. Entretanto, apenas um ano duraram os trabalhos com o alto-forno que foi substituído por um forno sueco, mais simples, conforme relata J. E. Pohl, um viajante estrangeiro em Minas Gerais de início do século XIX (Pohl, 1976:373-5; Alfonso-Goldfarb, 1994:145-6). Este não é, entretanto, um caso isolado, outro estrangeiro, Eschwege, engenheiro a serviço do governo português no Brasil, realizará severas críticas à maneira como se buscava produzir o ferro nos primeiros anos do Brasil-Reino (Eschwege, 1979; Alfonso-Goldfarb e Ferraz, 1994:218-9).

Apesar de o quadro colonial pouco alvissareiro, um plano para a institucionalização da ciência começa a se desenhar no período do Brasil já independente. Conforme já se viu, Derby estaria anunciando esse plano em seu artigo de 1883. Sob a égide de Pedro II modificam-se as antigas ou surgem novas instituições brasileiras dedicadas a dar força a empreendimentos do então novo país que se integrasse ao panorama da ciência internacional.

O interesse do Imperador pela ciência já é bem conhecido e o levou a apoiar atividades e instituições cien- tíficas, participando de sua organização, provendo fundos ou doando coleções particulares. É o caso do Instituto Histórico e Geográfico Brasileiro, instalado no palácio do Imperador, que recebeu sua biblioteca particular, além de uma coleção de retratos, gravuras e mapas antigos. Para incentivar seu funcionamento, D. Pedro chegou a presidir algumas das sessões periódicas. Também o colégio que leva até hoje o nome de Pedro II, o recebeu semanalmente, durante longos anos, para as chamadas "Conferências da Glória", que tiveram, muitas vezes, como tema as ciências naturais (Alfonso-Goldfarb e Ferraz, 1992a: 18-19).

No rol das instituições apoiadas por D. Pedro encontravam-se, por exemplo, aquelas em que Derby e outros estudiosos de seu naipe estariam realizando, efetivamente, investigações, como foram o Museu Nacional, o Observatório Nacional, a Escola Politécnica do Rio de Janeiro ou, ainda, a Escola de Minas de Ouro Preto. ${ }^{7}$ Dentre essas - exatamente por ser nova e estar relacionada a uma questão central do desenvolvimento científico no Brasil - merece especial atenção a Escola de Minas de Ouro Preto.

Historicamente, o interesse em mineralogia e metalurgia do Imperador intensifica-se, na década de 1870, quando de sua visita à Europa e aos Estados Unidos. Em Paris, D. Pedro visita, na Academia das Ciências, seu colega Daubrée - então diretor da Escola de Minas dessa cidade - a quem pede sugestões para conhecer e explorar o potencial mineral do Brasil. O ponto principal, segundo o professor francês, seria a criação de um estabelecimento de ensino na área de engenharia de minas. O Imperador pretendia que o próprio Daubrée viesse ao Brasil para dirigir essa escola, entretanto, estando impossibilitado, sugere o nome de Gorceix que, de fato, desloca-se ao Brasil em 1874.

Um ano depois, Gorceix já apresentava a D. Pedro II um projeto com informações sobre onde deveria estar localizada a escola e como deveria funcionar. Segundo o professor francês, o local privilegiado seria o centro mineral mais importante do Brasil, ou seja, a região de Ouro Preto, pois, dessa forma, estariam dadas as facilidades para se realizarem os trabalhos de investigação onde a prática e a experimentação teriam lugar nas questões teóricas - obrigatórias tanto para os professores quanto para os estudantes. Para inaugurar e manter em funcionamento a escola, seu diretor teve de lutar obstinadamente, ainda que contasse com o total apoio do Imperador. Uma das principais oponentes configurava-se na Escola Politécnica, criada a partir da Escola Central 
- oriunda, por sua vez, da Academia Real Militar -, em 1874 , que oferecia, desde esse ano, um curso de engenharia de minas.

O projeto de Gorceix feria o caráter livresco reinante no ensino brasileiro e que encontrava ecos também nessa instituição do Rio de Janeiro. Por outro lado, a localização da escola - longe da Corte - aliada à preparação deficiente, sobretudo em ciências, mas também em outras áreas, dificultava o recrutamento dos alunos. Tentando sanar esse último problema, Gorceix insiste e consegue do Imperador autorização para criar um curso preparatório, a ser seguido pelos candidatos ao curso de engenharia de minas. Muitos esforços foram despendidos para a manutenção da Escola de Minas. Entretanto, os alunos egressos dessa instituição tinham dificuldades para empregar-se como engenheiro de minas - sobretudo pelo fato de as grandes companhias mineradoras estarem nas mãos de estrangeiros que preferiram trazer os técnicos de que necessitavam de seu país - e, em pouco tempo, tornou-se necessário modificar os excelentes planos de Gorceix e conceder aos formados um título que o permitissem trabalhar como engenheiros civis (Carvalho, 1978; Alfonso-Goldfarb e Ferraz, 1992, 1999). Poucos anos após a deposição de D. Pedro, Gorceix abandona a Escola de Minas que já havia se distanciado muito dos planos iniciais de seu primeiro diretor e também dos do Imperador.

Com base nesse foco criado pela Escola de Minas, poderia ter sido formado um ponto para a interligação e desenvolvimento dos quatro componentes para a institucionalização das ciências no Brasil. Uma vez que houve um esforço concentrado para o ensino e pesquisa da melhor qualidade que deveria ter frutificado conforme publicações e aplicação de trabalhos metalúrgicos e mineralógicos. Tivesse vingado o projeto de Gorceix apoiado com grande energia pelo Soberano -, os trabalhos nessa área teriam-se espalhado como fogo por todo o território nacional, gerando, já aí, uma cadeia institucional que ligaria a Escola à indústria metalúrgica. ${ }^{8}$

$\mathrm{Na}$ verdade, Derby, embora esperançoso quanto às perspectivas futuras, admite os problemas desse projeto vigente de institucionalização da ciência. E apesar de sua brandura - até admitindo engenhosidade para questões de ciência - para com o patrono real, para consigo mesmo e o grupo de pesquisadores a que pertence, conclui seu artigo dizendo: "Se o progresso científico é lento, isto não será como antes devido à indiferença ou ignorância da verdadeira natureza da ciência. Mas, porque o desenvolvi- mento material do Império não permite as facilidades de pesquisa desfrutadas em países mais antigos e ricos" (Derby, 1883:214).

Outros comentadores - menos benevolentes com as perspectivas da cultura científica brasileira patrocinada pelo Imperador - apontariam já na escola as raízes para que o modelo institucional da ciência não vingasse no Brasil. Entre estes, o caso Agassiz que, vindo a convite do próprio Imperador, em 1865, para visitar o Brasil, comenta sobre uma das escolas brasileiras, no caso a Escola Central - que se transformaria, como se disse anteriormente, na Escola Politécnica em 1874 - que: "os cursos de matemática, química, física, ciências naturais são larga e seriamente feitos; porém mesmo nesse estabelecimento fiquei impressionado pela mesquinhez dos meios de demonstrações práticas e experimentais; os professores não me parecem haver suficientemente compreendido que as ciências físicas não se ensinam unicamente e principalmente pelos manuais" (Agassiz, 1938:593).

Opinião que se mantém na voz de um brasileiro ainda em finais do século XIX. Será este B.F.R. Galvão (Apud Barros, 1986:212-13) que diz: "se a Academia conta seus alunos por centenas, não é porque estas centenas de moços queiram seriamente aprender, mas, simplesmente ganhar um título que os habilite a escalar posições elevadas e o conforto da vida".

Galvão, que se tornaria, já no Brasil República, o primeiro reitor da também primeira e finalmente fundada Universidade do Brasil, afirma em um relatório oficial não ter dúvida de que a Universidade estava criada apenas in nomine e que de maneira alguma atendia a seu regimento quanto ao desejo de estimular a cultura da ciência. ${ }^{9}$

De fato, o problema da criação de centros de ensino e pesquisa que dessem base para o modelo institucional científico se manteria ainda durante várias décadas depois de entrado o século XIX. Os motivos variados que incluem desde a forte interferência do movimento positivista brasileiro até uma estranha visão das elites fundadoras de centros universitários mereceriam um capítulo à parte.

Basta lembrar que parte da luta do próprio D. Pedro para a fundação de centros universitários foi travada com positivistas como R.Teixeira Mendes que diz: "a ciência não lucra com semelhante criação porque a ciência nasceu sem privilégios e perseguida; cresceu e desenvolveu-se igualmente sem privilégios, e perseguida tam- 
bém. A proteção só serviu para profaná-la, aplicando-a contra os interesses sociais e em proveito de retrógrados e anarquistas. O país também não lucra: primeiro porque a Universidade vai consumir um capital enorme, melhor aplicado na elevação dos proletários; segundo porque vai dificultar a propagação da doutrina regeneradora, seja ela qual for; terceiro porque ataca a liberdade de pensamento; quarto porque aumenta o parasitismo burguês". ${ }^{10}$

Enquanto o reverso da moeda será visto, quase meio século depois, em um texto elaborado justamente por um dos fundadores da Universidade de São Paulo. Uma das primeiras universidades brasileiras e a primeira a manter dedicação exclusiva, pressupondo ensino associado à pesquisa, esse centro tinha como uma de suas metas, desde a fundação, desenvolver a ciência e criar os quadros necessários de cientistas no país. É, portanto, significativo que F. de Azevedo, um dos fundadores e autor do texto que se citará, tenha considerado como um dos problemas para o desenvolvimento da ciência no país a "mentalidade (ou falta de mentalidade) científica" dos brasileiros ao dizer: "foi, de fato, pelas ciências naturais que começou nossa cultura científica; e em nenhum outro domínio surgiu no Brasil maior número de pesquisadores, nem adquiriram maior importância as contribuições de brasileiros aos progressos dos estudos científicos. Mas, para isso devem ter concorrido não somente a imensa riqueza de nossas matas e de nossos campos em espécies vegetais, e o poderoso incentivo de numerosos naturalistas estrangeiros que [...] percorreram o Brasil [...] e o próprio caráter da história natural, que, tendo como primeiro objeto observar os seres vivos, descrevê-los e classificá-los, é de todas as ciências a mais acessível e a que, impondo o mesmo rigor de observação e a mesma exatidão na análise dos fatos, não exige o mesmo esforço intelectual, o mesmo poder de raciocínio e a mesma capacidade de espírito criador e de abstração" (Azevedo, 1963:379-80).

Diga-se que F. de Azevedo foi nomeado, em 1938, presidente da Comissão Censitária Nacional e que este texto introduz a publicação dos resultados do censo de 1940 , de onde emana um bom número dos indicadores que servirá às análises dos problemas brasileiros assim como à implementação de novas políticas... inclusive científicas. No entanto, parece que o problema histórico e sociológico identificado por F. de Azevedo não era exatamente a resposta para os problemas com a institucionalização científica no Brasil.
Por volta deste mesmo período, tornaram-se visíveis problemas com a outra ponta do processo de institucionalização no país, ou seja, a industrialização. Carrochefe desta industrialização, a siderurgia brasileira continuava encurralada pelos problemas já indicados: minérios muito ricos para os processos conhecidos, falta de carvão mineral, devastação de florestas para os fornos, etc. Esses problemas antigos passam a ter, historicamente, um recorte mais claro a partir de 1908. Nessa data as estimativas do mineral de ferro deixaram o mundo boquiaberto: $1 / 4$ de todo potencial mundial encontrava-se no Brasil. Todavia, a produção nacional era de apenas $17 \mathrm{mil}$ ton./ano contra as 550 ton./ano necessárias. Para que se tenha uma idéia de quão modestas eram as necessidades brasileiras - não alcançadas -, no México, país que pode ser comparado ao Brasil no período, já se produzia, desde o início do século, uma quantidade que determinava sua quase auto-suficiência ferrífera (Bastos, 1959:190; Lima, 1958:63; Alfonso-Goldfarb e Ferraz, 1992b:137).

Em países de parque industrial desenvolvido como os Estados Unidos, a produção siderúrgica - motor deste parque industrial - era feita sobretudo em fornos tocados a coque com uma pequena suplementação (aproximadamente $5 \%$ ) de fornos a carvão vegetal. O Brasil, naturalmente, com seu problema de carvão mineral para a produção do coque, parecia destinado, portanto, a nunca ter um grande parque siderúrgico (Silva, 1922:86-7).

São dessa época propostas para criar pequenas usinas de carvão vegetal associadas a fornos elétricos que pudessem suprir as necessidades brasileiras até que futuros avanços técnicos permitissem a criação de uma grande siderúrgica nacional. Nenhuma dessas propostas será efetivamente implementada e a Primeira Guerra Mundial trará ao Brasil problemas de importação de ferro já industrializado e o presidente Venceslau Brás, em discurso de 1918, ao final de seu mandato, dirá que o que existe no Brasil é uma "miniatura de siderurgia", mas de novo afirma que devem ser incentivadas as iniciativas com o uso do carvão vegetal, com o complemento de fornos elétricos, até surgirem outros processos que possam ser aplicados ao minério brasileiro. ${ }^{11}$

Naturalmente, sempre houve manifestações em contrário ao uso do carvão vegetal que, além de pouco eficiente, devastava as florestas, como foram as reflexões de Laboriau em seu estudo de 1924. Exemplo consumado de "cosmopolita", Laboriau considera inevitável e natural o uso de coque importado como única solução 
para o problema do país, e todas as outras propostas meras "patriotadas". ${ }^{12}$

O discurso de Laboriau e outros "liberais cosmopolitas" com grande influência no governo brasileiro tinha em mente, na verdade, a autorização dada pelo Congresso Nacional ao Presidente Epitácio Pessoa, em 1920, com vista à celebração de um futuro contrato com uma companhia estrangeira que desenvolvesse a grande siderurgia no Brasil com uso de coque importado. A companhia, neste caso, era a Itabira Iron Ore Company, que nessa época se tornara um consórcio anglo-americano. No entanto, já em seu formato original inglês, há vários anos vinha propondo e executando projetos indecorosos de exploração mineral no Brasil. Igualmente indecoroso seria o contrato autorizado pelo Congresso que concedia a outra companhia, além da isenção de impostos para importação de matéria-prima e equipamentos, o direito à construção e à exploração total das vias de transporte do minério até o monopólio de exploração do mineral. ${ }^{13}$ Esse contrato nunca chega a se realizar já que na própria lei que o autoriza (Lei $n^{\circ} 3.991$, de 05/01/1920) encontra-se o outro lado da moeda: dispositivos dirigidos a proteger a indústria nacional do ferro. ${ }^{14}$

Este jogo entre liberalismo cosmopolita e protecionismo nacionalista terá lances e contra lances de um lado e de outro durante quase uma década sem que nada de realmente novo acontecesse na indústria siderúrgica nacional. Entre discussões de gabinete a respeito do possível contrato com a Itabira Iron e leis que protegem e provêem de fundos pequenas usinas de carvão vegetal, aos poucos vão terminando com a mata original de Minas Gerais. Chegase ao início da década de 30 importando quase $65 \%$ do ferro necessário, com produção de $10 \mathrm{~kg} /$ ano per capita ( $3 \mathrm{~kg}$ a menos que a média dos países mais atrasados no oriente no mesmo período) (Azevedo, 1955:22-4; Bastos, 1959:224-5). Período bem conhecido por suas convulsões econômicas e sociais em que se está gestando uma guerra pelo mundo afora, esse período, como todos sabem, corresponde ao getulismo no Brasil. Getúlio Vargas decidira fazer da criação de uma grande indústria siderúrgica no país símbolo maior da nacionalidade brasileira. Fará, assim, uma série de ousadas negociações - aproveitando o clima de guerra - tanto com o Eixo como com os Aliados, desde 1939, conseguindo estabelecer, em 1946, a Companhia Siderúrgica Nacional (CSN). O acordo, feito com o governo americano, abre uma linha de crédito para o Brasil e facilita a transferência tecnológica - e de quebra autoriza Vargas a encerrar a longa negociação com a
Itabira Iron e nacionalizar os territórios ricos em minério de ferro que pertenciam a essa companhia (Gomes, 1983:201-4; 245-85; Bastos, 1959:171-271).

Essas negociações e a criação da CSN, que dependeram do clima excepcional da guerra, permitiram diminuir radicalmente as importações, com a produção de 50\% de ferro nacional numa única fábrica (Bastos, 1959:175; Bausbaum, 1991:151; Gomes, 1983:268).

$\mathrm{Na}$ verdade, porém, já na década de 50 , era do conhecimento que os altos custos para a criação da CSN desencadearam a dívida externa; que havia inúmeros problemas para resolver com o carvão mineral; que a tecnologia transferida era, ainda, raquítica e como conseqüência o ferro produzido, além de insuficiente, era caro. ${ }^{15}$

Efetivamente, as tradicionais e pequenas fábricas a carvão vegetal de Minas Gerais complementariam a produção ferrífera necessária ao parque automobilístico brasileiro então em crescimento (Alfonso-Goldfarb, Nascimento e Ferraz, 1993).

O diagnóstico e o cotidiano da produção de ferro na década de 50 demonstrariam que milagres históricos dificilmente acontecem, pois muitos dos antigos problemas com o rico minério continuavam em pauta. Ponta de lança da indústria nacional, a CSN, ao se pautar na transferência quase direta de tecnologia estrangeira não serviu como impulso a um processo de institucionalização que se adequasse às necessidades científicas e tecnológicas brasileiras.

Os dois binômios - ensino/pesquisa e divulgação/aplicação do conhecimento - parecem não ter tido um encaixe adequado nesse momento crucial da história brasileira.

Cresce, de fato, desde os anos 40, o parque industrial brasileiro, e, da mesma forma, o número de leitores da ciência brasileiros, não só da grande imprensa, mas também de periódicos cada vez mais especializados. E naturalmente aumenta também o número de centros universitários ou de pesquisa brasileiros a partir da década de 40. Ainda assim, é evidente que a articulação de um modelo institucional continuará com problemas (Sodré, 1977; Lima, 1976:347 e seg.)

Parece que não se passaram mais de 100 anos desde a publicação do provável artigo de Derby na revista Science, ao se ler, em 1989, o artigo da revista Nature que aponta as deficiências no quadro da ciência brasileira. Esta que foi uma reportagem de capa da revista, traz os mesmos tópicos, ou seja, excesso de burocracia, cultura bacharelesca, falta de adaptação das teorias científicas às ques- 
tões brasileiras, iniciativas isoladas, falhas na avaliação e financiamento dos trabalhos (Anderson, 1989).

No caso, tanto de Science, em 1883, como de Nature em 1989, o olhar estrangeiro fez um raio-X preciso e brutal de nossa realidade. No entanto, como sempre o paciente traduz melhor as causas de sua enfermidade, e os prognósticos doutos, mas forasteiros, nem sempre se cumprem.

Talvez um projeto que tenta integrar os quatro componentes necessários à definitiva institucionalização da ciência no Brasil tenha começado a delinear-se nesses últimos dez anos, rompendo com certas pré-concepções sobre a "mentalidade (ou falta) científica brasileira", "incapacidade" de investimento governamental, etc.

Novamente como reportagem de capa na revista Nature, de 13 de julho de 2000, laboratórios e cientistas brasileiros aparecem consorciados no projeto Genoma, um dos grandes focos da ciência na atualidade. Quem sabe, finalmente, estejamos delineando contornos mais bem definidos de um projeto que integre os quatro componentes para a institucionalização da ciência no Brasil.

Terminaria, assim, a longa série de tentativas, sem grandes resultados, pelas quais historicamente o Brasil passou desde sua época colonial.

\section{NOTAS}

Este artigo fundamenta-se em pesquisa desenvolvida com apoio Fapesp.

1. O artigo foi publicado no v.1, n.8 (30 de março) e teve a autoria estabelecida posteriormente por A. D. Gonsalves; ver Carvalho, 1978: 23; Filgueiras (1990), traduz e comenta partes desse artigo.

2. Esta obra, de que se salvaram alguns poucos exemplares, só voltou a ser publicada integralmente no século XIX; sobre as diferentes edições do livro de Antonil (1982) ver a "Nota bibliográfica" de F. Sales; para detalhes sobre o recolhimento e queima dos livros ver o "Estudo Biobibliográfico" de A. Taunay em Antonil (1982:21-59, especialmente p.31 e seg.).

3. De A.R. Ferreira, ver, por exemplo, "Diário da viagem filosófica pela Capitania de São José do Rio Negro", Revista do Inst. Hist. Geog. e Etnog. do Brasil, Rio de Janeiro, vs.48, 49, 50 e 51, 1885-1888; de Feijó, "Memória sobre a Capitania do Seará", O Patriota, Rio de Janeiro, Impressão Régia, v.1, 1814, p.46-62; de Couto, ver Memória sobre a Capitania de Minas Gerais, reimp. Belo Horizonte, Fund. João Pinheiro/Centro de Estudos Históricos e Culturais, 1994; já de Câmara, entre outros trabalhos, pode-se citar Memória sobre a cultura do algodão e sobre o método de o escolher e ensacar, etc., Lisboa, Tip. Calcográfica e Literária do Arco do Cego, 1799; Veloso foi diretor da Tipografia Calcográfica do Arco do Cego, depois Impressão Régia, em Lisboa e fez aí publicar importantes trabalhos destinados a nosso país como $O$ fazendeiro do Brasil, em 10 volumes, 1786-1806.

4. O livro de Léry, inicialmente publicado em 1578, recebeu, em 1980 (Belo Horizonte/São Paulo, Itatiaia/Edusp), a mais importante edição em português sob o título Viagem à terra do Brasil; já Thevet teve seu livro As singularidades da França Antártica publicado em nosso país em 1978 pelas mesmas editoras. De Piso ver, por exemplo, História natural do Brasil traduzida ao português e publicada apenas em 1948 pela Cia. Ed. Nacional; de Marcgraf, História natural e médica da Índia Ocidental, Rio de Janeiro, 1957.

5. Alguns dos textos publicados na Impressão Régia são: de Legendre, Tratado de geometria, 1809; de Fourcroy, Filosofia química, 1816; de Haüy, Tratado elementar de física, 1810; de Lacroix, Tratado elementar de aritmética, 1810; de Euler, Elementos d'Álgebra; de Bomtempo, Compêndios de matéria médica, 1814; e de Guimarães, Elementos de astronomia, 1814, na verdade uma compilação de textos sobre o tema (Camargo e Moraes, 1993:v.1).

6. A memória de Gomes foi apresentada à Academia das Ciências de Lisboa em 1803 e publicada em suas Memórias em 1812.

7. Além do próprio Derby, em seu artigo (1883:213) em que cita até os trabalhos que ele próprio está realizando, essas instituições são descritas, também, por Campos (1940).

8. Veja-se, por exemplo, o caso de J. Liebig, primeiro a estabelecer esse vínculo entre escola e indústria no segundo quartel do século XIX, mas que ainda dependeria de um longo processo para reprodução desse modelo em outros lugares. Ver: Rossiter, 1975.

9. Este relatório é citado por Nagle (1974:130).

10. Essa fala de Teixeira Mendes encontra-se em texto publicado pelo Centro Positivista Brasileiro em 1882 e está citado por Cunha (1986:99)

11. Mensagem presidencial dirigida pelo Presidente Venceslau Brás ao Congresso (Andrade, 1950:114-15).

12. F. Laboriau, O nosso problema siderúrgico, Rio de Janeiro, Bertrand, 1924 (Apud Gomes, 1983:187).

13. Ver Bastos, 1959:125; sobre a Itabira Iron, ver Couto, 1938:13 e seg. e, ainda, Silva, 1922.

14. Essa lei apoiada por outra de 1918 será usada, em 1922, por Epitácio Pessoa para promulgar o Decreto $n^{\circ} 15.493$ de 23/05/1922, que tinha como única beneficiária a Usina Queiroz Júnior, de Minas Gerais, com dois dispositivos legais que concediam os empréstimos necessários para cobrir toda a instalação da usina; ver Alfonso-Goldfarb, Nascimento e Ferraz, 1993.

15. Sobre o problema do combustível na indústria siderúrgica, ver Penna, 1949; Motta, 1949; Azevedo, 1955:25. Sobre a dívida nacional e os problemas com o coque nacional, ver Anônimo, 1950:96-7; $108 ; 112$ e seg.

\section{REFERÊNCIAS BIBLIOGRÁFICAS}

AGASSIZ, L. Viagem ao Brasil, 1865-66. São Paulo, Nacional, 1938.

ALFONSO-GOLDFARB, A.M. "Mirando a la historia de la minería desde otros enfoques: los informes extranjeros entre los siglos XVII e XIX". In: MARTOS, M.C. (org.). Minería e metalurgia; Intercambio tecnológico y cultural entre América y Europa durante el periodo colonial español. Sevilla/Bogotá, Muñoz Moya y Montraveta, 1994.

ALFONSO-GOLDFARB, A.M. e FERRAZ, M.H.M. "Reflexões sobre uma história adiada: trabalhos e estudos químicos e pré-químicos brasileiros". Quipu. México DF., Sociedade Latino-Americana de História da Ciência, v.5, n.3, set.-dez. 1988, p.339-53. 
. “A recepção da química moderna no Brasil”. Quipu. México DF., Sociedade Latino-Americana de História da Ciência, v.7, n.1, jan.-abr. 1990, p.73-91.

. "A institucionalização da metalurgia no Brasil: da Escola à praxis". Revista da Sociedade Brasileira da História da Ciência. São Paulo, Sociedade Brasileira da História da Ciência, v.7, jan.-jun. 1992a, p.15-24.

. "De lo nativo a lo nacional: reevaluando la cuestión siderúrgica brasileña”. Dynamis. Granada, Univ. de Granada, v.12, 1992b, p.131-49.

. "La transformación de las técnicas metalúrgicas y los problemas para la introducción de les estudios químicos: de BrasilColonia a Brasil-Imperio". In: PASTRANA, P.E.A. (orgs.). La química en Europa y América (siglos XVIII y XIX). México, DF., Univ. Autónoma Metropolitana, 1994.

. "Las miradas extranjeras/autóctonas sobre la terra brasilis independiente: ciencia y salud entre el Imperio y la Republica". In: SARMIENTO, F.J.P.; PÉREZ, M.E.A. e BUENO, M.R. (orgs.). 1898: Sanidad y ciencia en España y Latinoamérica durante el cambio de siglo. Madri, Doces Calles, 1999a.

. "Mining School of Ouro Preto: An Attempt to Establish Metallurgy in Brasil". Quipu. México DF., Sociedade LatinoAmericana de História da Ciência, v.12, n.1, jan./abr. 1999b, p. 25-37.

ALFONSO-GOLDFARB, A.M.; FERRAZ, M.H.M. e FIGUEIRÔA, S.F.M. "Diffuser les sciences 'dans un océan d'analphabétisme': singularités brésiliennes". In: BENSAUDE-VINVENT, B. e RAMUSSEN, A. (orgs.). La science populaire dans la presse et l'édition; XIXe et XXe siècles. Paris, CNRS, 1997.

ALFONSO-GOLDFARB, A.M.; NASCIMENTO, C.A.R. e FERRAZ, M.H.M. "Um estudo sobre a implantação da moderna siderurgia no Brasil: o caso da Usina Queiroz Júnior". Revista da Sociedade Brasileira da História da Ciência. São Paulo, Sociedade Brasileira da História da Ciência, v.10, jul.-dez. 1993, p.3-12.

ANDERSON, A. "Science in Brazil". Nature. Londres, Macmillan Magazines, v.342, n.6.248, 1989, p.327-460.

ANDRADE, A. de. Contribuição à história administrativa do Brasil; da República até o ano de 1945. v.2. Rio de Janeiro/São Paulo, José Olympio, 1950.

ANDRADE, V.N. “Academia Médico-Cirúrgica, Informação sobre o número de professores, vencimento dos mesmos e número de aluno". 1827. Biblioteca Nacional do Rio de Janeiro, Manuscritos, II-30, 33, 15, n.3.

[ANÔNIMO]. "Um novo capítulo em Volta Redonda". Observador Econômico e Financeiro. Rio de Janeiro, v.14, n.175, ago. 1950, p.82-125.

ANTONIL, J.A. Cultura e opulência do Brasil. Belo Horizonte/São Paulo, Itatiaia/Edusp, 1982.

AZEVEDO, F. de. A cultura brasileira. 4ª ed. Brasília, UnB, 1963.

AZEVEDO, M.D.M. de. O Rio de Janeiro: sua história, monumentos, homens notáveis, usos e curiosidades. v.2. Rio de Janeiro, Garnier, 1877.

AZEVEDO, R.F.R. de. "A grande siderurgia no Brasil”. Observador Econômico e Financeiro. Rio de Janeiro, v.20, n.237, nov. 1955, p.22-29.

BAETA, N. A indústria siderúrgica em Minas Gerais. Belo Horizonte, Imprensa Oficial, 1973.
BASTOS, H. A conquista siderúrgica do Brasil. São Paulo, Martins Fontes, 1959.

BARROS, R.M.S. A ilustração brasileira e a idéia de universidade. São Paulo, Edusp/Convívio, 1986.

BAUSBAUM, L. História sincera da República. São Paulo, AlfaÔmega, 1991.

BOMTEMPO, J.M. Compêndios de matéria médica. Rio de Janeiro, Impressão Régia, 1814.

CAMARGO, A.M. de A. e MORAES, R.B. de. Bibliografia de Impressão Régia do Rio de Janeiro (1808-1822). 2 v. São Paulo, Edusp/Kosmos, 1993.

CAMPOS, E.S. Instituições culturais e de educação superior no Brasil. Rio de Janeiro, Imprensa Nacional, 1940.

CARVAlHo, J.M. A Escola de Minas de Ouro Preto; o peso da glória. São Paulo/Rio de Janeiro, Nacional/Finep, 1978.

CORREIO BRAZILIENSE. Londres, W. Lewis \& Paternoster Row, v.1, 1808. Edição fac-similar. São Paulo/Brasília, Imprensa Oficial/ Correio Braziliense, 2001.

COUTO, J. V. Memória sobre a Capitania de Minas Gerais. Reimp. Belo Horizonte, Fund. João Pinheiro/Centro de Estudos Históricos e Culturais, 1994.

COUTO, R.M. A questão do ferro. Rio de Janeiro, Olímpica, 1938.

CUNHA, L.A. A Universidade Temporã. 2a ed. rev. e ampl. Rio de Janeiro, Francisco Alves, 1986.

CUNHA, P.O.C. da. "Política e administração de 1640 a 1764". In: HOLANDA, S.B. (org.). História Geral da Civilização Brasileira. I. A época Colonial. 2. Administração, Economia, Sociedade. Rio de Janeiro, Bertrand Brasil, 1993.

DERBY, O. "The Present State of Science in Brazil". Science. Washington, The Amer. Assoc. for the Advancement of Science, v.1, n.8, 30 mar. 1883, p.211-14.

FERRAZ, M.H.M. As ciências em Portugal e no Brasil (1772-1822). o texto conflituoso da química. São Paulo, Educ/Fapesp, 1997.

"Matière médicale luso-brésilienne au début du XIX" siècle". In: EMPTOZ, G. e PASTRANA, P.E.A. (orgs.). Between the Natural and the Artificial. Turnhout, Brepols, 2000, p.17380 .

FILGUEIRAS, C.A. "Origens da ciência no Brasil”. Química Nova. São Paulo, Sociedade Brasileira de Química, v.13, n.3, 1990, p.222-29.

GOMES, B.A. "Observationes botanico-medicae de nonnulis brasiliae plantis". Memórias, da Academia das Ciências de Lisboa. Lisboa, Academia, v.3, parte 1, 1812, p.202-42.

GOMES, F.M. História da siderurgia no Brasil. Belo Horizonte/São Paulo, Itatiaia/Edusp, 1983.

HALLEWELL, L. O livro no Brasil (sua história). São Paulo, T.A. Queiroz/Edusp, 1985.

LEINZ, V. “A Geologia e a Paleontologia no Brasil”. In: AZEVEDO, F. de (org.). As ciências no Brasil. São Paulo, Melhoramentos, [1954], p.243-63.

LIMA, H.F. História político-econômica e industrial do Brasil. São Paulo, Nacional, 1977.

"Panorama atual da Siderurgia". Observador Econômico e Financeiro, Rio de Janeiro, v.23, n.265, mar. 1958, p.60-7. 
MOACYR, P. A instrução e o império; subsidios para a história da educação no Brasil, 1823-1853, v.1. São Paulo, Nacional, 1936.

MOTTA, J.P. "Desenvolvimento da siderurgia brasileira em função do carvão mineral nacional e importado”. Geologia e Metalurgia. São Paulo, Centro Moraes Rego/Escola Politécnica-USP, n.7, out. 1949, p.11-5.

NAGLE, J. Educação e sociedade na Primeira República. São Paulo, Edusp/EPU, 1974.

PENNA, M.S. "Problema do carvão no Brasil”. Geologia e Metalurgia. São Paulo, Centro Moraes Rego/Escola Politécnica-USP, n.7, out. 1949, p.24-33.

POHL, J.R.E. Viagem no interior do Brasil. Belo Horizonte/São Paulo, Itatiaia/Edusp, 1976

ROSSITER, M.W. The Emergence of Agricultural Science; Justus Liebig and the Americans, 1840-1880. New Haven/Londres, Yale Univ. Press, 1975.
SILVA, R.R. da. O problema da siderurgia no Brasil e o contrato da Itabira iron Ore Company Limited. Rio de Janeiro, Associação dos Empregados do Comércio, 1922.

SODRÉ, N.W. História da imprensa no Brasil. 2a ed. Rio de Janeiro, Graal, 1977.

Ana Maria Alfonso-Goldfarb: Historiadora da Ciência, Coorde nadora do Programa de Pós-Graduação em História da Ciência e do Centro Simão Mathias de Estudos em História da Ciência da PUC-SP (belasartes@belasartes.com.br).

Márcia H.M. Ferraz: Historiadora da Ciência, Professora do Programa de Pós-Graduação em História da Ciência, Pesquisadora do Centro Simão Mathias de Estudos em História da Ciência da PUC-SP (mhferraz@pucsp.br). 